\title{
VENOUS THROMBOSIS AND PULMONARY EMBOLISM IN SPINAL CORD INJURY
}

\author{
By Norval Watson, M.B., Ch.B., D.P.H. \\ Spinal Injuries Unit, Lodge Moor Hospital, Sheffield
}

THIS survey was undertaken to determine the incidence and mortality of venous thrombosis and pulmonary embolism, occurring in cases of acute spinal cord injury which were admitted to the Spinal Injuries Unit, Lodge Moor Hospital, Sheffield, during the last Io years, I958 to 1967 inclusive. A total of 43 I patients were included in the survey. Only those cases admitted at an early stage following injury were included. Most of them were admitted within three days of injury and all within the first week. The numbers represent almost 80 per cent. of all cases of acute spinal cord injury admitted to the unit, the remaining 20 per cent. having been excluded from the survey because of delays in admission for various reasons.

Routine Management. All patients underwent the same routine management of change of position two-hourly by day and night, intermittent or continuous catheterisation, regular bowel evacuations by suppository or manual evacuation by staff, regulated fluid intake and diet. Physiotherapy was started as soon as the patients were fit enough, usually within the first three days of admission. Methods used included active exercises to intact musculature, passive movements to all paralysed groups, breathing exercises and assisted coughing for tetraplegics. Exercises were increased as the patient's general state allowed. Patients were allowed a self-lifting pole to assist their turns after about the sixth to eighth week and were allowed to sit out in a chair at the eighth to twelfth week, by which time the danger of venous thrombosis was past. Patients were nursed flat in the first few weeks, except cervical cases which commonly were nursed with the head of the bed slightly elevated to allow counter-traction from the skull calipers. The patient's leg, on the opposite side to that on which he was lying, was elevated on a pillow, so that each leg was only elevated a little for two hours in every six hours. The whole bed was never tilted head down. Blood transfusions were never given in the leg in this unit.

Purpose of the Survey. An analysis of the figures was carried out to determine the incidence of venous thrombosis and pulmonary embolism in acute spinal cord injury, and the relationship between these complications and several very variable factors.

These included:

I. Year of injury.

2. Level and type of lesion.

3. Site of thrombosis.

4. Time of onset of venous thrombosis and pulmonary embolism.

5. Mortality. 

6. Age.
7. Sex.
8. Associated injuries.
9. Major operations.

Incidence according to Year of Injury. Table I shows that the overall incidence of venous thrombosis was $12 \frac{1}{2}$ per cent. of the total cases at risk. Pulmonary embolism occurred in 5 per cent. and the mortality rate was $\mathrm{I} \frac{1}{2}$ per

TABLE I

Incidence according to Year of Injury

\begin{tabular}{|c|c|c|c|c|}
\hline & $\begin{array}{c}\text { Early } \\
\text { admissions }\end{array}$ & $\begin{array}{l}\text { Venous } \\
\text { thrombosis } \\
\text { cases }\end{array}$ & $\begin{array}{c}\text { Pulmonary } \\
\text { embolism } \\
\text { cases }\end{array}$ & $\begin{array}{c}\text { Mortality } \\
\text { deaths }\end{array}$ \\
\hline I958 & 36 & $2(6 \%)$ & I $(3 \%)$ & $0(0 \%)$ \\
\hline I959 & 46 & $6(13 \%)$ & $3(7 \%)$ & I $(2 \%)$ \\
\hline I960 & 37 & $6(16 \%)$ & $3(8 \%)$ & $2(5 \%)$ \\
\hline I96I & 45 & $3(7 \%)$ & $0(0 \%)$ & $\mathrm{O}(0 \%)$ \\
\hline I962 & 38 & $3(8 \%)$ & $0(0 \%)$ & $0(0 \%)$ \\
\hline I963 & 50 & $3(6 \%)$ & I $(2 \%)$ & $0(\%)$ \\
\hline 1964 & $6 I$ & $9(15 \%)$ & $2(3 \%)$ & $\mathrm{O}(0 \%)$ \\
\hline I965 & 43 & I I $(25 \%)$ & $8(18 \%)$ & $4(9 \%)$ \\
\hline I966 & 40 & $5(12 \%)$ & $3\left(7^{\circ}\right)$ & $0(0 \%)$ \\
\hline I967 & 35 & $6(17 \%)$ & I $(3 \%)$ & $0(0 \%)$ \\
\hline Total & $43 I$ & $54\left(\right.$ I $\left.2 \frac{1}{2} \%\right)$ & $22(5 \%)$ & $7\left(1_{2}^{1 \%} \%\right)$ \\
\hline
\end{tabular}

cent. The incidence varied markedly in various years, ranging between 6 per cent. and 25 per cent. One year, 1965, when the incidence reached 25 per cent., was particularly serious, as there was also an exceptionally high incidence of pulmonary embolism of I 8 per cent. with a mortality of 9 per cent. This single year, I965, accounted for more than half the total death rate. There was nothing untoward about the admission pattern for that exceptional year and the routine of the ward was not altered at that time. There were no deaths in seven out of the ro years surveyed.

The results are similar to that of Walsh at Stoke Mandeville (Walsh and Tribe, 1965), except that the mortality rate in the Sheffield series was only half that of the Stoke Mandeville series.

It is interesting to note that Walsh also reported one exceptional year.

Incidence according to Level and Type of Lesion. Table II demonstrates the incidence of venous thrombosis and pulmonary embolism in relation to the level and type of lesion. The numbers show the incidence at three levels of injury, cervical, dorsal and lumbar, and are further broken down to show the incidence in both types of lesion, complete and partial at each of these three levels. Mortality rates are also demonstrated. 
Analysis of Table II reveals several interesting features :

I. The incidence of venous thrombosis was higher in complete lesions (I8 per cent.) than in incomplete lesions (8 per cent.). This was true at all levels.

2. Dorsal lesions ( 23 per cent.) had a higher rate of venous thrombosis than cervical ( 9 per cent.) or lumbar injuries (I2 per cent.). Walsh and Tribe (1965) also recorded a high rate of venous thrombosis in complete dorsal injuries.

TABLE II

Incidence according to Level and Type of Lesion

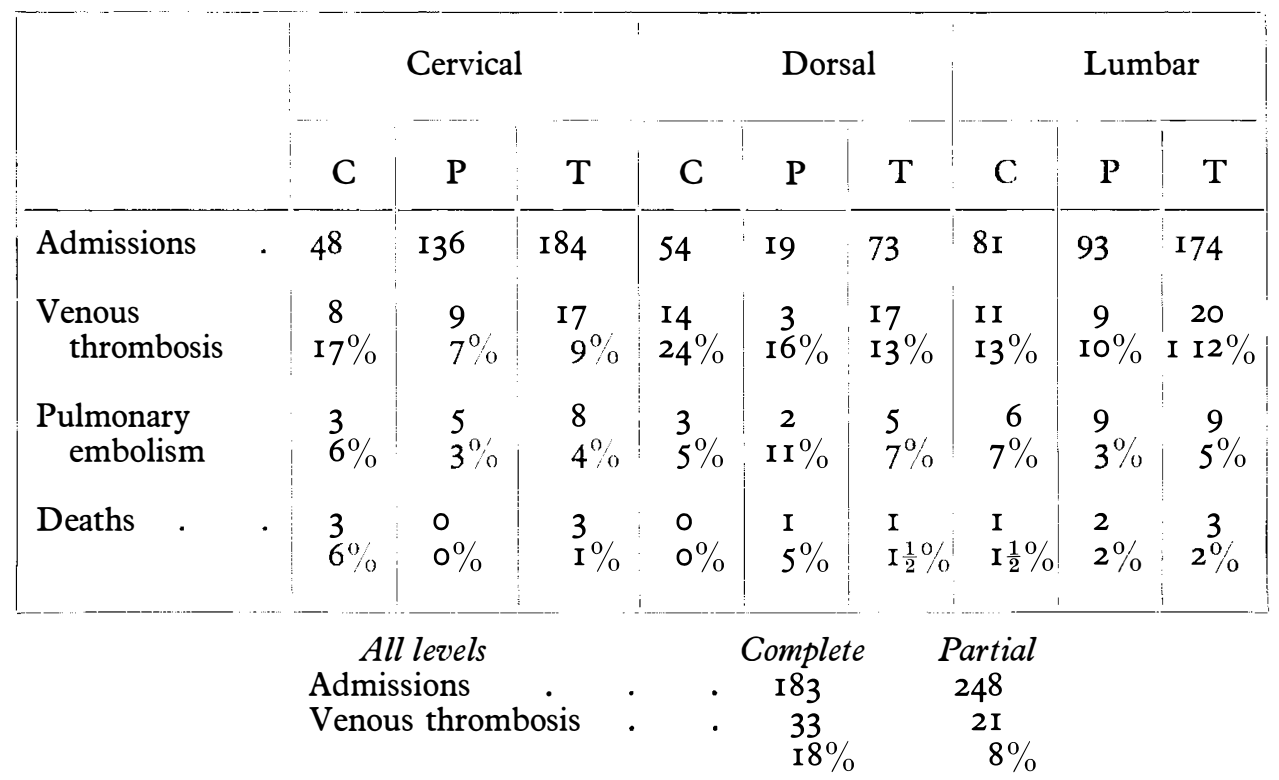

3. Despite this high rate of venous thrombosis in dorsal lesions, the incidence of pulmonary embolism in complete dorsal lesions was 5 per cent., compared with a rate of I I per cent. for partial dorsal injuries. This is in contrast with the rate of pulmonary embolism in complete and partial lesions at the cervical and lumbar levels which have a direct relationship to the incidence of venous thrombosis at these levels.

4. The mortality rates were similar for the three levels of injury at a rate of $\mathrm{I} \frac{1}{2}$ per cent., but showed a striking dissimilarity when analysed with regard to the type of lesion, complete or partial. The largest single group of patients at risk were those with partial tetraplegia (136). There were no deaths, however, in this group, despite an incidence of venous thrombosis and pulmonary embolism just above half the average rate. In the complete dorsal group, which had the highest incidence of venous thrombosis (24 per cent.) and a low rate of pulmonary embolism ( 5 per cent.) there were no deaths recorded.

Site of Thrombosis. The site of thrombosis is indicated in Table III. This reveals that the left leg is involved twice as often as the right leg in venous thrombosis and that occasionally both legs may be involved (Io per cent.). 
In a fatal case of pulmonary embolism, the pelvic veins were found to be the site of thrombosis at post-mortem examination.

\section{TABLE III}

Site of Thrombosis

Right leg in 17 cases $=32 \%$

Left leg in 37 cases $=68 \%$

In 5 cases-both legs were affected

In I case-inferior vena cava was involved

In I case-pelvic veins were involved

In a much smaller series from Edinburgh, Philipps (1963) also found a higher incidence of venous thrombosis in the left leg.

Time of Onset of Venous Thrombosis after Injury. Table IVA indicates the frequency at which venous thrombosis occurred in relation to the time following injury. Venous thrombosis occurred most commonly about three

\section{TABLE IVA}

Time of Onset of Venous Thrombosis after Injury

$$
\begin{aligned}
& \text { Within I week . . . } \quad I=2 \% \\
& \text { Within I month } \quad \cdot \quad \cdot \quad \cdot 38=72 \% \\
& \text { Within } 2 \text { months . . . } \quad 7=12 \% \\
& \text { Within } 3 \text { months . . . } 8=14 \%
\end{aligned}
$$

weeks after trauma. When it occurred two to three months after injury, the thrombosis was usually minor or superficial, it hardly ever caused pulmonary embolism and it never caused death. Some authorities (Benassy, 1965) have suggested that the transfer of a patient during the critical period two to four weeks after injury should be avoided if possible and that if transfer is imperative the patient should receive prophylactic anticoagulant therapy.

Time of Onset of Pulmonary Embolism. Table IVB indicates the frequency at which pulmonary embolism occurred in relation to the interval

\begin{tabular}{|c|c|c|}
\hline At the same $t$ & s thror & IO $=45 \%$ \\
\hline With & & \\
\hline Within 2 weeks & & $4=\mathrm{I} 8 \%$ \\
\hline in 4 weeks & . & $3=14 \%$ \\
\hline Within 8 weeks & . & $2=9 \%$ \\
\hline
\end{tabular}
between the date of venous thrombosis and the onset of pulmonary embolism.

\section{TABLE IVB}

Time of Onset of Pulmonary Embolism

Half the cases of pulmonary embolism occurred without previous warning of venous thrombosis. It is unlikely that cases of venous thrombosis would have 
been missed prior to embolism as the staff were always on the alert for this complication and the legs were handled every two hours. The serious major infarcts occurred without warning or within one to two weeks of venous thrombosis. Those infarcts occurring after four weeks were usually minor episodes.

Analysis of Deaths. Tables VA and VB indicate the pattern of death and its time of occurrence following injury. It demonstrates that most of the deaths occurred without any previous warning of venous thrombosis. It also confirms

\section{TABLE VA \\ Analysis of Deaths}

$\begin{array}{ll}\text { Sudden death without previous venous thrombosis } & 5 \\ \text { Death occurring after venous thrombosis had been } & \\ \text { noted I to } 2 \text { weeks previously } & 2 \\ & 7\end{array}$

TABLE VB

Time of Death following Injury

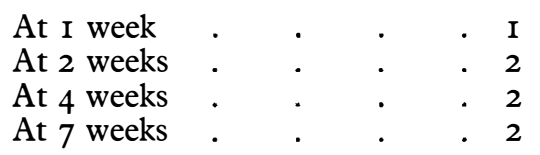

the findings in Table IVв that the major infarcts occurred without warning. Of the ro cases of pulmonary embolism which occurred without warning as in Table IVB, five were instantly fatal, i.e. 50 per cent.

The only method of reducing the mortality from pulmonary embolism would be to institute anticoagulant therapy to all patients with an acute spinal cord injury from the first week of admission. This would not be justified with regard to the present mortality rates.

Age of Cases. Table VI indicates the average ages of the patients at risk, the patients with complications and those who died. The figures are very similar.

\section{TABLE VI \\ Age of Cases}

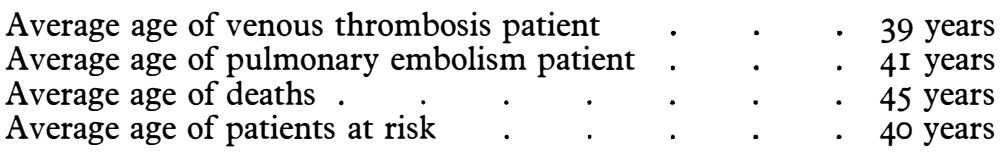

The age at death ranged from 34 to 54 years, so that the very young and the very old were not in danger of death. Nevertheless, the very young had a fair incidence of venous thrombosis. On the other hand, the incidence of complications in the over 60 years group was quite low, only three cases of venous thrombosis, two of whom developed pulmonary embolism. 
Sex Incidence. The incidence of venous thrombosis, pulmonary embolism and death with regard to the sex of the patient is indicated in Table VII. These figures only relate to the period 1962 to 1967 , as females were not admitted prior to this period.

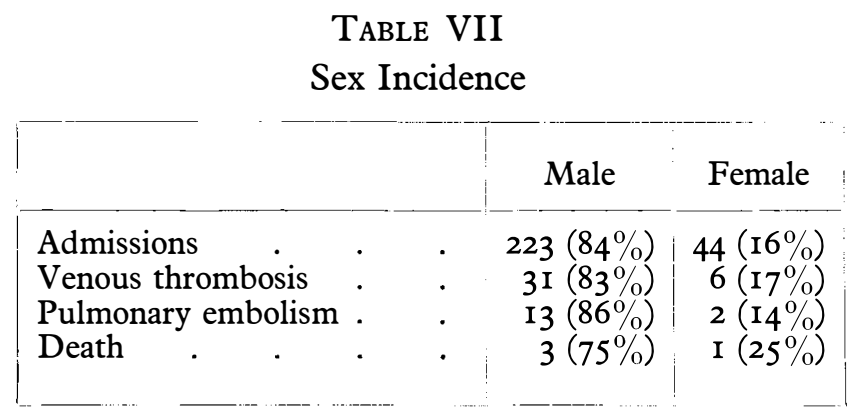

The results show that the incidence of complications and death showed no variation with the sex of the patient.

Incidence of Complications in association with Other Injuries. Table VIII indicates the frequency with which complications occurred in those cases of acute spinal cord injury which were associated with other injuries sustained in the same accident.

TABLE VIII

Incidence in association with Other Injuries

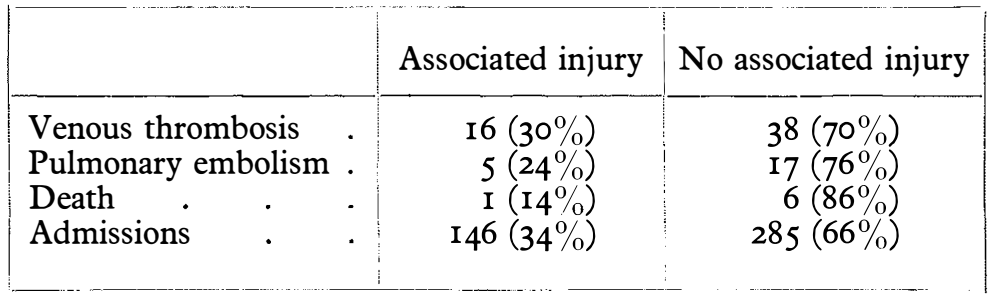

The results showed that there was no increased incidence of complications or death when an associated injury was sustained.

Of the I6 cases with associated injuries who developed complications, 13 had chest injuries, two had head injuries and one had a renal complication. The one death had chest injuries.

Incidence of Complications in association with Major Operations. Table IXA indicates the relative frequency with which venous thrombosis and pulmonary embolism occurred in association with a major operation carried out on a patient with an acute spinal injury. It demonstrates that there was no increased incidence of complications when an operation was performed. Indeed, there was a reduced incidence of pulmonary embolism and only one death in the group who required operation. 
Over the years 1958 to 1967 there has been a gradual change in the admission pattern with an increase in the number of cervical injuries, a decrease in the number of lumbar injuries, and also a more selective approach to major operations, which have greatly decreased in number over the period.

TABLE IXA

Incidence in association with Major Operations

\begin{tabular}{|l|r|r|} 
& Major operation & No operation \\
\hline Venous thrombosis & $\mathrm{I} 2(22 \%)$ & $42(78 \%)$ \\
Pulmonary embolism . & $4(\mathrm{I} 8 \%)$ & $\mathrm{I} 8(82 \%)$ \\
Death & $\mathrm{I}(\mathrm{I} 4 \%)$ & $6(86 \%)$ \\
Total patients at risk & $\mathrm{IO8}(25 \%)$ & $323(75 \%)$ \\
\hline
\end{tabular}

It was thought convenient to analyse the results in two major 5-year groups to determine whether the incidence of venous thrombosis had altered as the pattern of admissions and the frequency of operation changed.

Table IX $\mathrm{B}$ indicates the relationship clearly and it demonstrates that the incidence of venous thrombosis has increased moderately as the frequency of major operations has markedly reduced.

\begin{tabular}{|c|ccc|c|}
\hline & \multicolumn{3}{c}{ TABLE IXB } & \\
\hline & Admissions & Major operations & Venous thrombosis \\
\hline 195862. & $\cdot$ & 202 & $73(37 \%)$ & $20(10 \%)$ \\
$1963-67$. & $\cdot$ & 229 & $34(14 \%)$ & $34(15 \%)$ \\
\hline
\end{tabular}

The patients with lumbar spinal cord injury were the only groups subjected to major operative procedures and Table IXc indicates the incidence of venous thrombosis in this group in relation to whether a major operation was performed

TABLE IXC

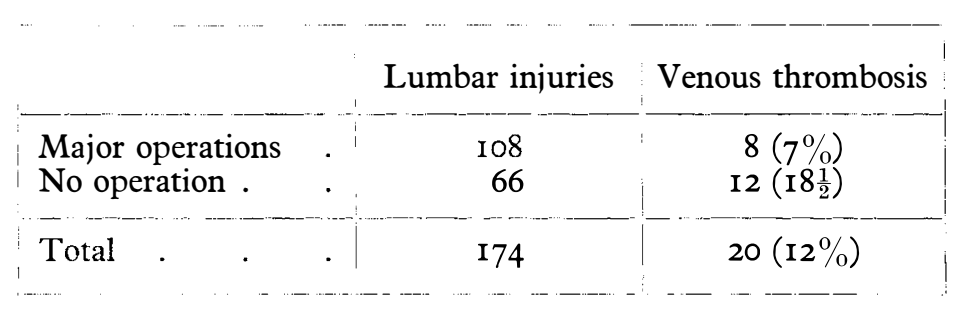

or not. From these figures it is evident that the incidence of venous thrombosis in the group which were subjected to major operation ( 7 per cent.) was less than half that of the group treated conservatively (I8 per cent.). 
Table II demonstrated that the highest incidence of venous thrombosis occurred in dorsal injuries which practically never underwent surgery and that the incidence of complications in lumbar injuries, in which group all the surgery was performed, was only average.

Treatment. It is difficult to assess the results of treatment with anticoagulants, as the treatment policy has changed over the years. In earlier years only cases of pulmonary embolism were treated, but in more recent years most cases of venous thrombosis have been treated. As has been noted previously, most of the deaths have occurred suddenly without previous warning of venous thrombosis. The two deaths, which occurred one to two weeks after venous thrombosis had been recognised, had not been treated with anticoagulants, so that in fact no deaths have occurred in any case which survived long enough and received treatment. There is no doubt that the disability arising from venous thrombosis has been much reduced when treatment has been given.

In the last year, 1967, six cases of venous thrombosis have occurred. All received anticoagulant therapy and there has been only one minor infarct with no deaths.

\section{SUMMARY}

This paper concerns a study of the morbidity and mortality of venous thrombosis and pulmonary embolism in $43 \mathrm{I}$ cases of acute spinal cord injury.

The incidence is related to age, sex, year of injury, level and type of lesion, type of onset and site of thrombosis, associated injuries and major operations.

The commonest time of occurrence was about three weeks after the initial trauma.

Dorsal lesions had the highest rate of venous thrombosis and its occurrence was higher in complete lesions than in incomplete lesions.

The mortality rates were similar at all levels of spinal cord injury. Variations and anomalies are briefly discussed.

The disability arising from venous thrombosis has been much reduced by the use of anticoagulant therapy. The prophylactic use of anticoagulants is not recommended.

\section{RÉSUMÉ}

Cet article comporte une étude de la morbidité et de la mortalité des thromboses veineuses et des embolies pulmonaires étudiée sur $43 \mathrm{I}$ cas de traumatismes médullaires à la période aìgue.

L'incidence est étudiée en considération de l'âge, du sexe, de l'année de la lésion, du niveua et du type de la lésion, des circonstances de l'accident, de la localisation de la thrombose, des lésions associées et de l'intervention chirurgicale majeure éventuelle.

Les premiers symptômes apparaissent environ trois semaines après la lésion initiale.

Le pourcentage des thromboses veineuses était plus élevé dans les lésions dorsales et également plus important dans les lésions complètes que dans les atteintes incomplètes.

Le pourcentage de mortalité était similaire à tous les niveaux segmentaires.

Les variations et anomalies ont été brièvement discutées.

Les séquelles de la thrombose veineuse ont été diminuées par l'utilisation de la thérapie anticoagulante. Par contre, l'utilisation de celle-ci dans un but profilactique n'est pas recommandé. 


\section{ZUSAMMENFASSUNG}

Untersuchungen über Morbidität und Mortilität venöser Thrombose und pulmonaler Embolie, ausgeführt an 43 I Fällen von akuter Rückenmarksverletzung, werden berichtet.

Die Häufigkeit des Auftretens dieser Störungen werden in Beziehung gebracht mit Alter, Geschlecht, Jahr der Verletzung, Höhe und Art der Läsion, Art des Beginns und Lokalisation der Thrombose, assoziierten Verletzungen und grösseren Operationen. auf.

Thrombose und Embolie traten am häufigsten drei Wochen nach dem initialen Trauma

Venöse Thrombose wurde häufiger in kompletten Läsionen gefunden.

Die Mortalitätsrate war die gleiche in allen Höhen der Rückenmarksverletzung. Variationen und Anomalien werden diskutiert.

Die Folgeerscheinungen der venösen Thrombose sind durch die Anwendung der Antikoagulationstherapie erheblich vermindert worden. Eine prophylaktische Antikoagulation wird aber nicht empfohlen.

\section{REFERENCES}

Benassy, J. (1965). Int. F. Paraplegia, 3, 2 II.

Philipps, R. S. (1963). Int. F. Paraplegia, I, I 17.

Walsh, J. J. \& Tribe, C. (1965). Int. F. Paraplegia, 3, 209. 